\title{
Brain responses to obesogenic diets and diet-induced obesity
}

\author{
Zoë A. Archer and Julian G. Mercer* \\ Division of Obesity and Metabolic Health, Rowett Research Institute, Aberdeen AB21 9SB, UK
}

\begin{abstract}
Rodent models of diet-induced obesity (DIO) mimic common human obesity more accurately than obese single-gene mutation lines, such as the $o b / o b$ mouse. Sprague-Dawley rats sourced in the UK develop obesity when fed a high-energy diet, but susceptibility to DIO is normally distributed, as might be anticipated for a polygenic trait in an outbred population, in contrast to reports in the literature using ostensibly the same strain of rats sourced in the USA. Nevertheless, the responses of these rats to solid and liquid obesogenic diets are very similar to those reported elsewhere, and this model of DIO has much to commend it as a vehicle for the mechanistic study of susceptibility to DIO, development and reversal of obesity on solid and liquid diets and the response of peripheral and central energy balance systems to the development of obesity and to the obesogenic diets themselves. In general, hypothalamic energy-balance-related systems respond to obesogenic diets and developing obesity with activity changes that appear designed to counter the further development of the obese state. However, these hypothalamic changes are apparently unable to maintain body weight and composition within normal limits, suggesting that attributes of the obesogenic diets either evade the normal regulatory systems and/or engage with reward pathways that override the homeostatic systems. Since diets are a risk factor in the development of obesity, it will be important to establish how obesogenic diets interact with energy-balance pathways and whether there is potential for diets to be manipulated with therapeutic benefit.
\end{abstract}

\section{Hypothalamic neuropeptides: Liquid diets: Overconsumption}

\section{Human obesity}

A small number of energy-balance genes are known to be essential for normal body-weight regulation, with lossof-function mutations in a single gene leading to obesity in laboratory animal models and in small numbers of human subjects (Hebebrand et al. 2003). The clustering of essential body-weight genes around the leptin-melanocortin receptor axis is particularly striking (Montague et al. 1997; Clement et al. 1998; Krude et al. 1998). This proofof-concept, however, does not explain obesity in the majority of the human population, in whom no such genetic changes have been identified. If obesity is entirely genetic in causation, it would be difficult to explain the substantial increase in prevalence that is apparent over the last few decades. Rather, the consensus position that is currently favoured within the scientific community is that susceptibility to obesity is encoded by cumulative small (in function) changes in a number of genes, which in combination establish a susceptible genotype that can in turn generate an obese phenotype when the individual is placed in an appropriate environment. Current lifestyle trends that minimise the amount of essential physical activity, whilst simultaneously providing ready access to palatable highlynutritious energy-dense food, have resulted in such a 'risk' environment. Contemporary diets are a major factor in the current obesogenic environment, and most human obesity could probably be assessed as being diet-induced.

\section{Obesogenic diets}

The majority of dietary manipulations that are applied experimentally to induce obesity in laboratory rodents have as their primary or only purpose the production of an obese animal, and may not be directly analogous to the types of diets consumed by individuals in the developed world. For example, commercial pellet diets, although available with a range of macronutrient compositions, are usually fed as the only source of nutrition, and in the absence of choice may oblige the animal to consume an unbalanced diet. If interest is in the mechanistic basis of overconsumption and how diets interact with peripheral and central (brain) energy-balance systems to induce obesity, there is a case 
(a)

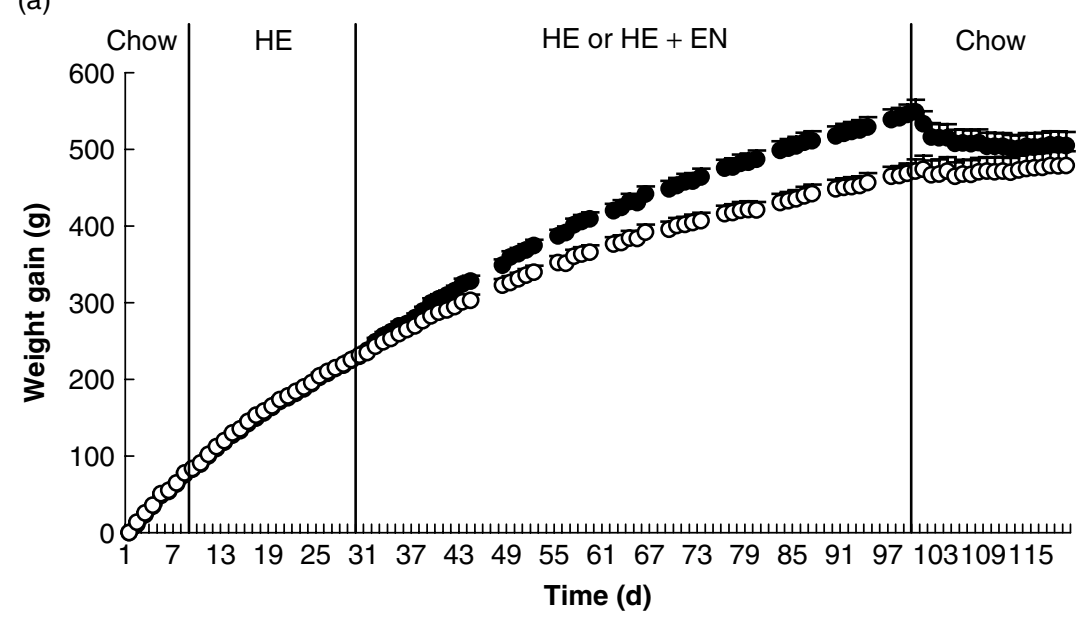

(b)

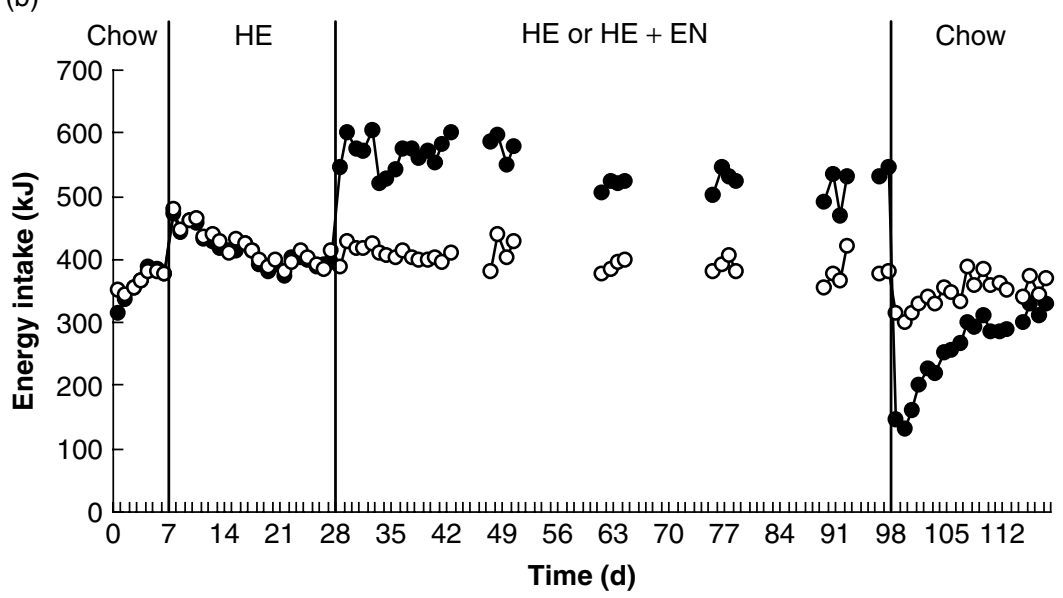

Fig. 1. Body-weight gain (g; a) and energy intake (kJ; b) of male Sprague-Dawley rats fed chow for $7 \mathrm{~d}$, followed by high-energy diet (HE) for $21 \mathrm{~d}(n 80)$, after which half the animals remained on the HE diet $(O ; n$ 40) and half had HE diet supplemented with Ensure $^{\circledR}$ (a palatable liquid diet; Abbott Laboratories, Queenborough, Kent, UK; EN; O; $n$ 40) for 10 weeks. On day 98, animals were transferred back to chow. (Data from Archer et al. 2005a.)

for attempting more subtle manipulations. This approach might involve the provision of dietary choices, e.g. the supply of fat or sugar in separate feeding containers or of energy in liquid form. The latter approach may be especially important not only since soft drinks, shakes, yoghurt drinks and fruit-puree products are an important source of energy in contemporary Western diets (Stubbs \& Whybrow, 2004), but also since human studies have recognised that energy-containing fluids generally induce less satiety than solids of equivalent energy content and carbohydrate load (DiMeglio \& Mattes, 2000), paralleling findings in rats (Sclafani \& Xenakis, 1984; Ramirez, 1987).

\section{Diet-induced obesity models and manipulations in the Sprague-Dawley rat}

From the earlier discussion it can be argued that rodent models of diet-induced obesity (DIO) may provide the best parallels of much human obesity, and such models now form a major research focus. Several distinct experimental strategies have been adopted in the study of DIO. These strategies have compared the effects of an obesogenic diet with a control diet in a single strain of rodent, the responses of two rodent strains (with differential susceptibility to DIO) to an obesogenic diet (Madiehe et al. 2000) or the range of DIO responses to an obesogenic diet within a single strain of rodent. The outbred Sprague-Dawley (SD) rat model exemplifies the latter approach, where individual animals within the population exhibit heterogeneity in their response to dietary challenge in a manner analogous to human subjects (Levin et al. 1989; Lauterio et al. 1994).

In the authors' hands exposure of the SD rat to a highenergy (HE) diet that is relatively high in both fat and sugar induces a relatively brief spell of hyperenergetic intake at the point of diet transition (Fig. 1(b)), which may be a result of the greater energy density of the HE diet, and 
an accelerated rate of weight gain. A normal distribution of body-weight gain has been consistently observed (Archer et al. 2003), with some individuals being relatively susceptible to excessive weight gain whereas others are relatively resistant. By contrast, ostensibly in the same rat strain, Levin and colleagues (Levin \& Dunn-Meynell, 2000; Levin \& Keesey, 1998; Levin, 1999; Lauterio et al. 1999) report the emergence of distinct subpopulations of individuals that are apparently either predisposed to develop obesity or are resistant to excessive weight gain. Whatever the precise experimental outcome, the involvement of an underlying genotype in relative susceptibility to DIO in these rats is indicated by the ability to selectively breed towards contrasting weight-gain phenotypes (Levin et al. 1997).

Studies of the SD rat model have also suggested that the diet composition is an important factor in determining the longer-term consequences of body-weight gain. The consequence of withdrawing an obesogenic diet on subsequent body-weight trajectory, i.e. the level of body weight that will subsequently be defended, depends on the diet fed during the development of obesity. This relationship is demonstrated in a number of studies of dietary transitions employing chow, an HE diet and the palatable liquid diet, Ensure ${ }^{\circledR}$ (Abbott Laboratories, Queenborough, Kent, UK; Ensure ${ }^{\circledR}$ is a complete balanced nutritional supplement formulated for the dietary management of patients with, or at risk of developing, diseaserelated malnutrition, and is employed in studies of diet-induced obesity because of its ability to stimulate overall energy intake (palatability) and its ability to promote a state of positive energy balance (energy density, macronutrient composition)). SD rats show near complete defence of body weight on transfer from HE diet back to chow (Fig. 1(a); Levin, 1999; Levin \& Dunn-Meynell, 2002; Archer et al. 2003; 2005a), in contrast to the effect of withdrawing $\mathrm{HE}+$ Ensure $^{\circledR}$. In the SD rat model liquid Ensure ${ }^{\circledR}$ was originally characterised as producing obesity in that proportion of the outbred population that was resistant to obesity on the HE diet (Levin, 1999). It has subsequently been demonstrated that Ensure ${ }^{\circledR}$ induces sustained energy overconsumption (Fig. 1(b)) and weight gain in the whole population of rats (Mercer \& Archer, 2005). However, the excess body weight and obesity that develops when Ensure ${ }^{\circledR}$ is provided as a supplement to the HE diet is not completely defended when rats are returned to chow (Levin, 1999; Levin \& Dunn-Meynell, 2002; Archer et al. 2005a). Weight loss on transfer from $\mathrm{HE}+$ Ensure $^{\circledR}$ to chow is driven by a substantial and sustained hypoenergetic feeding episode (Fig. 1(a)), the magnitude of which is correlated with the proportional contribution of Ensure ${ }^{\circledR}$ to total energy intake immediately before the dietary manipulation (Archer et al. 2005a). Similar responses in terms of overconsumption and hypoenergetic intake on withdrawal are observed when Ensure $^{\circledR}$ is employed as a supplement to chow pellet (chow + Ensure $^{\circledR}$; ZA Archer and JG Mercer, unpublished results). The following is a discussion of feeding studies designed to assess whether these outcomes are the result of feeding liquid diets or reflect the engagement of the diet with specific brain signalling systems.

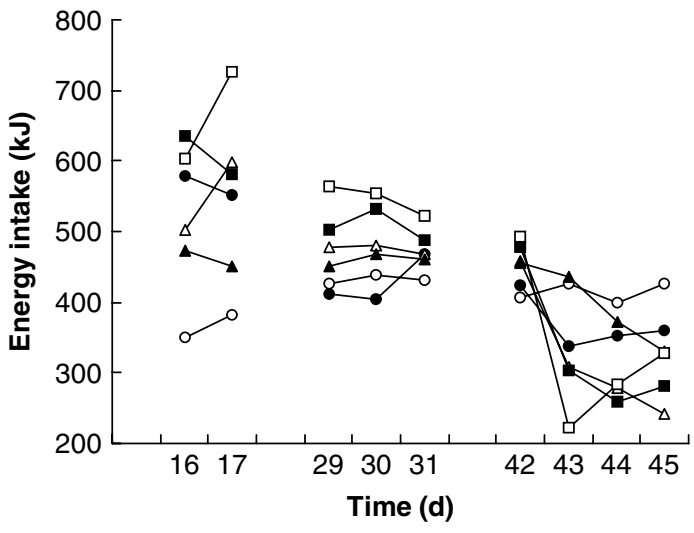

Fig. 2. Effects on energy intake of five different obesogenic diet formulations (chow, $\bigcirc$; high-energy (HE) pellet, O; Ensure ${ }^{\circledR}$ (a palatable liquid diet; Abbott Laboratories, Queenborough, Kent, UK), $\triangle$; HE liquid, $\boldsymbol{\Delta}$; chow + Ensure ${ }^{\circledR}, \square$; HE pellet + Ensure ${ }^{\circledR}$, for details, see p. 126) and their subsequent withdrawal and return to chow. Obesogenic diets were introduced on day 16 and withdrawn on day 43.

The earlier data indicate that overconsumption of energetic liquids is not dependent on an unbalanced macronutrient composition, such as in soft drinks that contain only carbohydrates. To investigate the nature of the stimulus to overconsume that is provided by the liquid Ensure $^{\circledR}$ diet, a small trial has been conducted in which the effects of some of the diets tested earlier (chow, HE pellet, chow + Ensure $^{\circledR}$, HE + Ensure ${ }^{\circledR}$ ) was compared with HE liquid (same macronutrient composition but soluble formulation) or Ensure ${ }^{\circledR}$ alone (Fig. 2). The effect of withdrawal of the obesogenic diets and return to chow was also assessed. Obesogenic diets were introduced on day 16 and withdrawn on day 43. It was observed that maximum energy intake occurs over days 16-17 and 29-31 and on day 42 in the chow + Ensure $^{\mathrm{R}}$ group, for which there is also a substantial hypoenergetic effect on return to chow only. The HE liquid is not overconsumed to any great extent after initial presentation, and there is no immediate hypoenergetic episode on withdrawal. Rats fed on Ensure ${ }^{\circledR}$ alone have a similar energy intake to that of the HE-liquid group but exhibit a more immediate and sustained withdrawal effect equivalent to that in the $\mathrm{HE}+$ Ensure $^{\mathbb{R}}$ group. These data suggest that the supply of an obesogenic diet as a liquid is not sufficient in itself to drive overconsumption and that the hypoenergetic episode on return to chow is not the consequence of the gastrointestinal tract having to readapt to a solid diet from one that was either mainly or exclusively liquid in formulation.

\section{Hypothalamic energy-balance systems}

Mammals regulate energy balance (intake and expenditure), and thus their body weight and composition, through the integration of numerous signals of neural, metabolic, endocrine and neuroendocrine origin. Signals reflecting and regulating energy balance originate both peripherally and within brain integratory centres. Peripheral signals relay the consequences of meal processing, gastrointestinal 


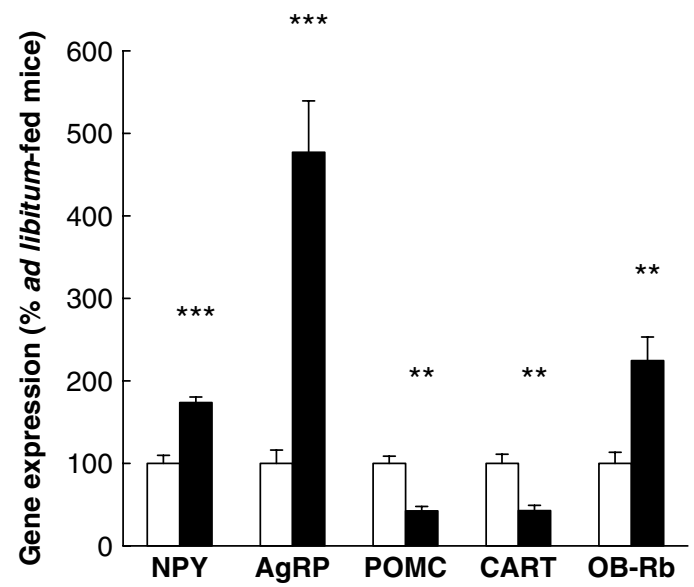

Fig. 3. Regulation of neuropeptide $Y$ (NPY), agouti-related peptide (AgRP), pro-opiomelanocortin (POMC), cocaine- and amphetamineregulated transcript (CART) and leptin receptor (OB-Rb) gene expression in the hypothalamic arcuate nucleus of mice food restricted to approximately $50 \%$ ad libitum intake for $96 \mathrm{~h}$ (ם). ( $\square$ ), Ad libitum-fed mice. Values are means with their standard errors represented by vertical bars. Mean values were significantly different from those for the ad libitum-fed mice: ${ }^{\star \star} P<0.01,{ }^{\star \star \star} P<0.001$.

activity and changes in energy stores. Such signals may reach the brain directly, crossing the blood-brain barrier from the systemic circulation, or they may involve changes in the firing rate of vagal or other sensory nerve fibres. Within the hindbrain and the hypothalamus at the base of the forebrain is contained the neural circuitry for the integration of peripheral signals and subsequent onward signal transmission. The hypothalamus plays a key role in energy homeostasis, and changes in the activity of neuroendocrine systems in this region are likely to modulate both intake and expenditure, including both conservation and dissipation of energy. The last three decades have seen an explosion in research into these circuits, catalysed by the cloning of the obesity gene leptin, and there is now detailed knowledge of the neuronal populations involved in regulating energy balance, the orexigenic (anabolic) and anorexigenic (catabolic) molecular substrates involved, and their regulation and integration (Friedman \& Halaas, 1998; Kalra et al. 1999; Schwartz et al. 2000; Berthoud, 2002).

The most-well-characterised role for hypothalamic energy-balance-related neuropeptide systems is in the compensatory response to negative energy balance. Energybalance systems in the hypothalamus are sensitive to the absence of food or its limited supply, and to the feedback signals reflecting this state, such as low blood leptin levels. Low circulating leptin acts on leptin receptors in the hypothalamic arcuate nucleus (ARC) to increase expression of orexigenic neuropeptides such as neuropeptide $\mathrm{Y}$ and agouti-related peptide and decrease expression of anorexigenic genes such as pro-opiomelanocortin and cocaineand amphetamine-regulated transcript (CART). These coordinated and complementary changes in hypothalamic gene expression (Fig. 3) effectively programme the animal to conserve energy while food supplies remain limited and to express hyperphagia once food becomes available again. These changes, and others, contribute to the familiar compensatory response to negative energy balance, but whereas this role is well described and appropriate in an evolutionary context to minimise the risk of starving to death and to accelerate recovery from severe negative energy balance, sensitivity of the same systems to positive energy balance is much less well studied (Mercer \& Speakman, 2001). Similar evolutionary pressures could have acted to limit excessive storage of surplus energy as fat, which could impact negatively on the ability of the individual to evade predators (Mercer \& Speakman, 2001). The limited evidence that is available supports this contention. Feeding via a gastric catheter at approximately $125 \%$ normal energy intake, producing $5 \%$ weight gain over $9 \mathrm{~d}$, reduced voluntary oral intake of pellet diet to $<10 \%$ that of controls, and increased expression of the anorexigenic genes corticotrophin-releasing factor and proopiomelanocortin by $50 \%$ and $80 \%$ in the paraventricular nucleus (Seeley et al. 1996) and ARC (Hagan et al. 1999) respectively. Thus, involuntary overfeeding appears to set in train a sequence of changes in peripheral and central signalling systems that culminate in voluntary hypophagia that may involve the melanocortin system (Hagan et al. 1999). This change in gene expression does seem to be effective in reducing energy intake. Examination of hypothalamic energy-balance systems under circumstances of voluntary overfeeding, such as in DIO, addresses issues of sensitivity to dietary manipulation and subtle changes in body weight over longer periods. How do the energybalance systems interact with diet in the regulation of body weight in the normal animal? Are apparent changes in the activity of energy-balance systems as a result of feeding obesogenic diets effective in limiting weight gain? With these questions in mind, the interaction of diet with hypothalamic energy-balance systems in the SD DIO model is being examined.

\section{Response of hypothalamic systems to obesogenic diets and diet-induced obesity}

Panels of cloned neuropeptide and receptor genes have been used to investigate the consequences of feeding obesogenic diets and the development of DIO on expression of candidate energy-balance genes. A growing body of evidence from the authors' (Archer et al. 2004, 2005a,b) and other laboratories (Guan et al. 1998; Lin et al. 2000; Ziotopoulou et al. 2000) indicates that the activities of energybalance-related hypothalamic and peripheral signals are affected by such manipulations and their consequences. For example, juvenile SD rats fed HE diet for 5 weeks develop a phenotype of normal weight but excessive adipose tissue accumulation (Archer et al. 2004) and exhibit a profile of hypothalamic gene expression that is consistent with data obtained from mice (Guan et al. 1998; Lin et al. 2000 ) and could represent a compensatory response counteracting the state of positive energy balance. Rats fed the HE diet have lower levels of neuropeptide Y, agoutirelated protein, leptin receptor and melanocortin-3 receptor mRNA in the ARC (Fig. 4; Archer et al. 2004). Neuropeptide $\mathrm{Y}$ and leptin receptor mRNA are also lower in the 


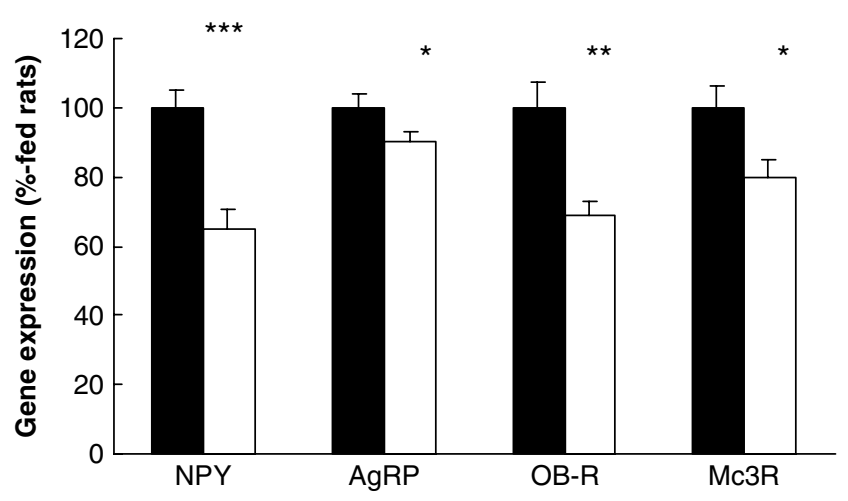

Fig. 4. Down-regulation of neuropeptide $Y$ (NPY), agouti-related peptide (AgRP), leptin receptor (OB-R) and melanocortin-3 receptor (Mc3R) mRNA in the hypothalamic arcuate nucleus (ARC) of rats fed chow diet $(\boldsymbol{\square})$ for 1 week and then the chow diet or the highenergy diet $(\square)$ for 5 weeks. Values are means with their standard errors represented by vertical bars. Mean values were significantly different from those for the rats fed the chow diet: * $P<0.05$, ${ }^{* *} P<0.01$, ${ }^{* *} P<0.001$. (Data from Archer et al. 2004.)

dorsomedial and ventromedial hypothalamic nuclei respectively. Reduced expression of orexigenic peptides and down-regulation of leptin receptor expression is consistent with the elevated circulating leptin concentrations that accompany DIO.

Changes in gene expression after 5 weeks on HE diet could be the consequence of excessive accumulation of adipose tissue, although there is also evidence of more immediate recognition of obesogenic diets at the hypothalamic level. Such recognition and recruitment of compensatory hypothalamic mechanisms may be a means of limiting weight gain (Ziotopoulou et al. 2000). In short- to medium-term studies (Archer et al. 2005b) CART gene expression is increased in the ARC of HE-fed animals after $12 \mathrm{~h}$, whereas melanocortin- 4 receptor mRNA is elevated in the paraventricular nucleus of HE animals at $24 \mathrm{~h}$. As has been repeatedly observed, SD rats initially overconsume energy when switched to an energy-dense HE diet, and the early increase in CART gene expression induced by positive energy balance may act to reduce food intake and increase energy expenditure. Whereas there may be recognition of obesogenic diets at the hypothalamic level, it is less clear whether regulatory systems can differentiate between different diets and the levels of obesity that develop as a consequence of their ingestion. The data accumulated suggests that such differentiation may not occur.

Hypothalamic gene expression has been measured in the animals represented in Fig. 1 (see Table 1; Archer et al. 2005a). Ensure ${ }^{\circledR}$ was fed as a supplement to the HE pellet diet in adult SD rats, resulting in sustained hyperenergetic intake, additional weight gain and adiposity, and elevated leptin; the animals from both the $\mathrm{HE}$ and $\mathrm{HE}+$ Ensure $^{\circledR}$ groups were then returned to chow. The effects of Ensure ${ }^{\circledR}$ supplementation on hypothalamic gene expression are very limited, in contrast to the effect on energy intake and weight gain. Only tyrosine kinase B mRNA in the ventromedial nucleus is affected by Ensure ${ }^{\circledR}$ supplementation,
Table 1. Hypothalamic gene expression in the arcuate nucleus (ARC) and ventromedial nucleus (VMH) of rats subjected to dietary manipulation* (analysis of data from Archer et al. 2005a)

\begin{tabular}{lccc}
\hline Gene & Nucleus & $\begin{array}{c}\text { Effect of } \\
\text { Ensure }\end{array}$ & $\begin{array}{c}\text { Effect of } \\
\text { transfer back } \\
\text { to chow }\end{array}$ \\
\hline NPY & ARC & $\leftrightarrow$ & $\uparrow$ \\
AgRP & ARC & $\leftrightarrow$ & $\leftrightarrow$ \\
POMC & ARC & $\leftrightarrow$ & $\leftrightarrow$ \\
CART & ARC & $\leftrightarrow$ & $\downarrow$ \\
Leptin receptor (OB-Rb) & ARC & $\leftrightarrow$ & $\leftrightarrow$ \\
Ghrelin receptor & ARC & $\leftrightarrow$ & $\leftrightarrow$ \\
DYN & ARC & $\leftrightarrow$ & $\downarrow$ \\
DYN & VMH & $\leftrightarrow$ & $\downarrow$ \\
Cannabinoid receptor-1 & VMH & $\leftrightarrow$ & $\leftrightarrow$ \\
BDNF & VMH & $\leftrightarrow$ & $\downarrow$ \\
TrkB & VMH & $\uparrow$ & $\leftrightarrow$ \\
\hline
\end{tabular}

NPY, neuropeptide Y; AgRP, agouti-related peptide; POMC, pro-opiomelanocortin; CART, cocaine- and amphetamine-regulated transcript, DYN, dynorphin; BDNF, brain-derived neurotrophic factor; TrkB, BDNF receptor; $\leftrightarrow$, no change; $\uparrow$, increase; $\downarrow$, decrease.

*Male Sprague-Dawley rats were fed chow for $7 \mathrm{~d}$, followed by high-energy diet (HE) for $21 \mathrm{~d}(n 80)$, after which half the animals remained on the $\mathrm{HE}$ diet $(n 40)$ and half had HE diet supplemented with Ensure ${ }^{\circledR}$

(a palatable liquid diet; Abbott Laboratories, Queenborough, Kent, UK; $n$ 40) for 10 weeks. On day 98 , animals were transferred back to chow. †Abbott Laboratories, Queenborough, Kent, UK.

with higher levels of expression observed in Ensure ${ }^{\circledR}$-fed rats. Tyrosine kinase $\mathrm{B}$ is the receptor for the anorexigenic peptide brain-derived neurotrophic factor, and is a human obesity gene (Yeo et al. 2004). Although the genes examined fail to differentiate between the two diets and their respective consequences, the changes in gene expression on return to the chow diet are again consistent with both sets of animals attempting to resist obesity during the period in which they were fed an obesogenic diet. There are changes in expression for four mRNA, neuropeptide Y, CART, brain-derived neurotrophic factor and dynorphin. The up- and down-regulation respectively of neuropeptide $\mathrm{Y}$ and CART gene expression in the ARC following transfer back to chow, coupled with the decrease in brainderived neurotrophic factor expression in the ventromedial nucleus appears to represent an integrated attempt to oppose further weight gain while on the obesogenic diets. The parallel down-regulation of dynorphin gene expression in both the ARC and the ventromedial nucleus on transfer back to chow indicates that this system is up regulated by the obesogenic diets employed, as reported elsewhere (Welch et al. 1996). The apparent insensitivity of the hypothalamus to Ensure ${ }^{\circledR}$ supplementation in these adult rats may reflect insensitivity to the additional elevation of the leptin signal over and above that produced by the HE diet.

Although the hypothalamic energy-balance systems may have limited capacity to distinguish between different obesogenic diets and the consequences of their ingestion, at least in older rats, the evidence of compensatory regulation of these systems is substantial and growing. However, despite the assessment that the homeostatic systems are changing in activity in a manner consistent with attempts to oppose further weight gain, the animal 
continues to develop obesity. At least in the case of the Ensure $^{\circledR}$ diet, this state of positive energy balance is driven on by substantial and sustained overconsumption of energy. This finding suggests that other attributes of the obesogenic diet override the regulatory capacity of the homeostatic systems. In the case of Ensure ${ }^{\circledR}$, the reward circuits are very likely to be involved (Kelley et al. 2003).

\section{Interactions between hypothalamic homeostatic systems and the reward circuits}

As discussed earlier, a substantial and growing body of evidence supports the existence of homeostatic mechanisms for regulating the consumption of food. However, it is equally apparent that reward systems contribute to a hedonic response to food in both man and laboratory mammalian species (Saper et al. 2002); for most human subjects food consumption goes beyond simply restoring energy reserves, and involves a complex array of sensory experiences, including olfactory, gustatory, social and visual cues. The 'pleasure' derived from the consumption of $\mathrm{HE}$ and sweet foods is likely to have been beneficial during evolution to encourage consumption of such foodstuffs when available. However, in the present environment in which $\mathrm{HE}$ foods are available in limitless quantities, it is likely to be contributing to the obesity epidemic. The circuits and molecules underlying the hedonic regulation of feeding are much-less-well studied than those that underlie the homeostatic mechanisms, although there are a number of candidate molecular and neuroanatomical components of the reward system, such as the opioid peptides, cannabinoids and the dopaminergic system, located in brain regions including the amygdala and the nucleus accumbens. The hedonic regulation of food intake may function independently of metabolic need, in contrast to the theoretical functioning of homeostatic regulation. Preferred foods appear to engage reward, or motivational, circuitry in the brain. The reward pathways are already viewed as a potential target for antiobesity therapeutics, as demonstrated by the advanced state of development of the cannabinoid CB1 receptor antagonist rimonabant (SR-141716). However, this field remains relatively underdeveloped in terms of scientific knowledge. Interactions between the homeostatic and hedonic systems are not well understood, but are likely to be important in the overall regulation of food intake and body weight. Rodent models of DIO offer the opportunity to examine food reward as a causative factor in much human obesity.

\section{Overview}

Different obesogenic diets bring about their effects on body weight and composition in different ways; for example, through sustained overconsumption or as a result of an unbalanced macronutrient profile. In general, there appears to be recognition of developing obesity at the hypothalamic level, although substantial changes in the activity of hypothalamic energy-balance systems are not able to prevent weight gain. Other attributes of the diet must be involved in thwarting this hypothalamic output, and engagement with the reward system is likely to be important. The mechanisms underlying features of the SD rat DIO model such as overconsumption of Ensure ${ }^{\circledR}$ and the hypoenergetic intake on its withdrawal, a phenomenon also observed following withdrawal of a solid 'cafeteria'type diet (Rogers, 1985), are likely to be of widespread relevance in common human obesity. In particular, more mechanism-based research at the homeostatic-reward-diet interface should prove profitable.

\section{Acknowledgements}

This work was funded by the Scottish Executive Environment and Rural Affairs Department (SEERAD) and the European Commission, Quality of Life and Management of Living Resources, Key action 1 'Food, nutrition and health' programme (QLK1-2000-00515).

\section{References}

Archer ZA, Rayner DV, Barrett P, Balik A, Duncan JS, Moar KM \& Mercer JG (2005a) Hypothalamic energy balance gene responses in the Sprague-Dawley rat to supplementation of high-energy diet with liquid Ensure and subsequent transfer to chow. Journal of Neuroendocrinology 17, 711-719.

Archer ZA, Rayner DV, Duncan JS, Bell LM \& Mercer JG (2005b) Introduction of a high energy (HE) diet acutely upregulates hypothalamic CART, Mc4R and brown adipose tissue UCP1 gene expression in male Sprague-Dawley rats. Journal of Neuroendocrinology 17, 10-17.

Archer ZA, Rayner DV \& Mercer JG (2004) Hypothalamic gene expression is altered in underweight but obese juvenile male Sprague-Dawley rats fed a high energy diet. Journal of Nutrition 134, 1369-1374.

Archer ZA, Rayner DV, Rozman J, Klingenspor M \& Mercer JG (2003) Normal distribution of body weight gain in male Sprague-Dawley rats fed a high energy (HE) diet. Obesity Research 11, 1376-1383.

Berthoud H-R (2002) Multiple neural systems controlling food intake and bodyweight. Neuroscience and Biobehavioral Reviews 26, 393-428.

Clement K, Vaisse C, Lahlou N, Cabrol S, Pelloux V, Cassuto D et al. (1998) Mutation in the human leptin receptor gene causes obesity and pituitary dysfunction. Nature 392, 398-401.

DiMeglio DP \& Mattes RD (2000) Liquid versus solid carbohydrate: effects on food intake and body weight. International Journal of Obesity 24, 794-800.

Friedman JM \& Halaas JL (1998) Leptin and the regulation of body weight in mammals. Nature 395, 763-770.

Guan XM, Yu H, Trumbauer M, Frazier E, Van der Ploeg LH \& Chen H (1998) Induction of neuropeptide Y expression in dorsomedial hypothalamus of diet-induced obese mice. Neuroreport 9, 3415-3419.

Hagan MM, Rushing PA, Schwartz MW, Yagaloff KA, Burn P, Woods SC \& Seeley RJ (1999) Role of the CNS melanocortin system in the response to overfeeding. Journal of Neuroscience 19, 2362-2367.

Hebebrand J, Friedel S, Schauble N, Geller F \& Hinney A (2003) Perspectives: molecular genetic research in human obesity. Obesity Reviews 4, 139-146.

Kalra SP, Dube MG, Pu S, Xu B, Horvath TL \& Kalra PS (1999) Interacting appetite-regulating pathways in the hypothalamic regulation of body weight. Endocrine Reviews 20, 68-100. 
Kelley AE, Will MJ, Steininger TL, Zhang M \& Haber SN (2003) Restricted daily consumption of a highly palatable food (chocolate Ensure(R)) alters striatal enkephalin gene expression. European Journal of Neuroscience 18, 2592-2598.

Krude H, Biebermann H, Luck W, Horn R, Brabant G \& Gruters A (1998) Severe early-onset obesity, adrenal insufficiency and red hair pigmentation caused by POMC mutations in humans. Nature Genetics 19, 155-157.

Lauterio TJ, Bond PJ \& Ulman EA (1994) Development and characterization of a purified diet to identify obesitysusceptible and resistant rat populations. Journal of Nutrition 124, 2172-2178.

Lauterio TJ, Davis MJ, DeAngelo M, Peyser M \& Lee J (1999) Neuropeptide Y expression and endogenous leptin concentrations in a dietary model of obesity. Obesity Research 7, 498-505.

Levin BE (1999) Arcuate NPY neurones and energy homeostasis in diet-induced obese and resistant rats. American Journal of Physiology 276, R382-R387.

Levin BE \& Dunn-Meynell AA (2000) Defence of body weight against chronic caloric restriction in obesity-prone and -resistant rats. American Journal of Physiology 278, R231$\mathrm{R} 237$.

Levin BE \& Dunn-Meynell AA (2002) Defence of body weight depends on dietary composition and palatability in rats with diet-induced obesity. American Journal of Physiology 282, R46-R54.

Levin BE, Dunn-Meynell AA, Balkan B \& Keesey RE (1997) Selective breeding for diet-induced obesity and resistance in Sprague-Dawley rats. American Journal of Physiology 273, R725-R730.

Levin BE, Hogan S \& Sullivan AC (1989) Initiation and perpetuation of obesity and obesity resistant rats. American Journal of Physiology 256, R766-R771.

Levin BE \& Keesey RE (1998) Defence of differing body weight set points in diet-induced obese and resistant rats. American Journal of Physiology 274, R412-R419.

Lin S, Storlien LH \& Huang XF (2000) Leptin receptor, NPY, POMC mRNA expression in the diet-induced obese mouse brain. Brain Research 875, 89-95.

Madiehe AM, Schaffhauser AO, Braymer DH, Bray GA \& York DA (2000) Differential expression of leptin receptor in high- and low-fat-fed Osborne-Mendel and S5B/Pl rats. Obesity Research 8, 467-474.

Mercer JG \& Archer ZA (2005) Diet-induced obesity in the Sprague-Dawley rat: dietary manipulations and their effect on hypothalamic neuropeptide energy balance systems. Biochemical Society Transactions 33, 1068-1072.

Mercer JG \& Speakman JR (2001) Hypothalamic neuropeptide mechanisms for regulating energy balance: from rodent models to human obesity. Neuroscience and Biobehavioural Reviews 25, 101-116.

Montague CT, Farooqi IS, Whitehead JP, Soos MA, Rau H, Wareham NJ et al. (1997) Congenital leptin deficiency is associated with severe early-onset obesity in humans. Nature 387, 903-908.

Ramirez I (1987) Feeding a liquid diet increases energy intake, weight gain and body fat in rats. Journal of Nutrition 117, 2127-2134.

Rogers PJ (1985) Returning 'cafeteria-fed' rats to a chow diet: negative contrast and effects of obesity on feeding behaviour. Physiology and Behavior 35, 493-499.

Saper CB, Chou TC \& Elmquist JK (2002) The need to feed: homeostatic and hedonic control of eating. Neuron 36, 199-211.

Schwartz MW, Woods SC, Porte D Jr, Seeley RJ \& Baskin DG (2000) Central nervous system control of food intake. Nature 404, 661-671.

Sclafani A \& Xenakis S (1984) Influence of diet form on the hyperphagia-promoting effect of polysaccharide in rats. Life Sciences 34, 1253-1259.

Seeley RJ, Matson CA, Chavez M, Woods SC, Dallman MF \& Schwartz MW (1996) Behavioral, endocrine, and hypothalamic responses to involuntary overfeeding. American Journal of Physiology 271, R819-R823.

Stubbs J \& Whybrow S (2004) Beverages, appetite and energy balance. In Beverages in Nutrition and Health, 1st ed., pp. 261-278 [T Wilson and NJ Temple, editors]. Totowa, NJ: Humana Press Inc.

Welch CC, Kim EM, Grace MK, Billington CJ \& Levine AS (1996) Palatability-induced hyperphagia increases hypothalamic dynorphin peptide and mRNA levels. Brain Research 721, 126-131.

Yeo GS, Connie Hung CC, Rochford J, Keogh J, Gray J, Sivaramakrishnan S, O'Rahilly S \& Farooqi IS (2004) A de novo mutation affecting human TrkB associated with severe obesity and developmental delay. Nature Neuroscience 7, 1187-1189.

Ziotopoulou M, Mantzoros CS, Hileman SM \& Flier JS (2000) Differential expression of hypothalamic neuropeptides in the early phase of diet-induced obesity in mice. American Journal of Physiology 279, E838-E845. 